\title{
Optimal Control of DC motor using Equilibrium Optimization Algorithm
}

\author{
Mamta \\ Department of Electrical Engineering \\ DAV Institute of Engineering \& Technology \\ Jalandhar, Punjab
}

\author{
Baljit Singh \\ (Assistant Professor) \\ Department of Electrical Engineering \\ DAV Institute of Engineering \& Technology \\ Jalandhar, Punjab
}

\begin{abstract}
In DC motor control operation, regulating the PID controller parameters is a major problem. To crack this difficulty, a new metaheuristic algorithm, Equilibrium Optimization Algorithm (EOA), is employed and planned for driving DC motor to discover the global best solution in search space. The controller proposed here in this paper can be used to optimally tune proportional-integral-derivative (PID) controller parameters. The results were obtained through simulation which show that the controller proposed in this work can efficiently perform search for the optimal PID controller. Simulation results also show that performance is improved in developing the speed loop response stability, the steady state error is decreased, the rising time is reaches perfection and the performances of driving motor are not affected by the disturbances with no overtaking.
\end{abstract}

Keywords - Ant Lion Optimizer; DC motor; PID controller; Parameter Optimization.

\section{INTRODUCTION}

In this contemporary era of industrialization, there is barely any industrial application or area where DC motors are not employed [1,2] and the reasons behind the wide use of DC Motors are control is easier, low expenditure on maintenance especially of a brushless DC motor, low cost, and ruggedness. Some main manufacturing and industrial applications in which DC motors are effectively used are machine tools, paper mills, textile industry, electric traction, and robotics. Owing to the fact that armature and field windings can be controlled independently, the controller design of DC motors is really flexible [3]. Mostly during speed control of DC motors, the current in field winding is kept constant and the current in armature winding is varied or vice versa which gives outstanding speed control performance over an extensive range of desired values. In such applications, the motive is to keep a track of the speed command by keeping the output speed at a particular desired level and to attain a desired speed or position control in least time without resulting in huge overshoots and settling times $[4,5]$.

By now there are several different types of controllers developed such as lead, lag, LQR (linear quadratic regulator), PID, and sliding-mode controller that can be incorporated in many control applications [6-8]. Out of these types of controllers, PID controller is considered to be one of the earliest and best controllers which is efficiently employed in almost every industrial control application due to its efficiency and ease of execution [9]. Although there are numerous traditional techniques for designing and tuning PID controller parameters $(K p, K i, K d)$, but these techniques come with a disadvantage of requirement of certain expertise and experience to handle such work because in these methods a hitand-trial approach is used to provide an initial point and achieving anticipated performance fine tuning of parameters. Hence, in view of this limitation metaheuristic approach may prove to be a better choice. Over a few years, many metaheuristic and stochastic optimization algorithms have been developed to solve many problems of almost every field and every discipline of life [10-12]. Mostly these techniques have evolved from nature and depend on the swarm intelligence, evolutionary, or foraging activities of diverse species. Some of the broadly used artificial intelligence practices are genetic algorithm (GA), particle swarm optimization (PSO), and simulated annealing (SA). In this paper, a PID controller design is used for speed control of DC motor and a recently developed Equilibrium optimization algorithm is used for fine tuning of the parameters of PID controller.

\section{MATHEMATICAL MODEL OF DC MOTOR}

By the following set of expressions, it can be seen that how a DC motor behaves dynamically [19] and the block diagram is represented by the figure below

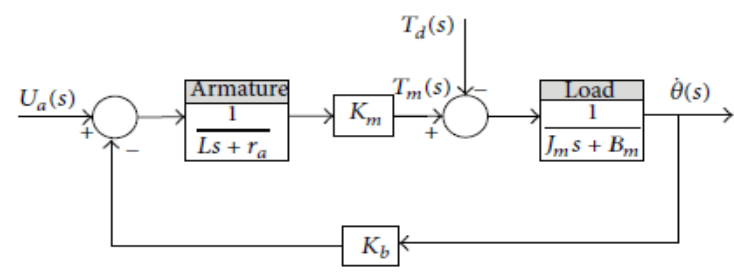

After ignoring certain nonlinearities such as backlash and dead zone, a simplified linear model is developed in order to simplify the implementation of metaheuristic techniques. Consider

$\mathrm{T}_{\mathrm{m}}(\mathrm{s})=\mathrm{k}_{\mathrm{m}} \mathrm{I}_{\mathrm{a}}(\mathrm{s})$

$U_{a}(s)=\left(r_{a}+L s\right) I_{a}(s)+U_{b}(s)$

$U_{b}(s)=K_{b} \theta(s)$,

$I_{a}(\mathrm{~s})=\frac{U_{a}(s)-K_{b} \theta(s)}{r_{a}+L s}$

$T_{l}(s)=J_{m} s^{2} \theta(s)+B_{m} s \theta(s)$

$T_{l}(s)=\mathrm{T}_{m}(\mathrm{~s})-T_{d}(s)$ 
where $U_{a}$ is applied voltage, $U_{b}$ is back-emf, $K_{m}$ is motor constant, $K_{b}$ is back emf constant, $J_{m}$ is inertia of rotor, $B_{m}$ is viscous damping, $T_{m}$ is developed motor torque, $T_{l}$ is torque delivered to load, $T_{d}$ is disturbance torque, $r_{a}$ is armature resistance, $L$ is armature inductance, $I_{a}$ is armature current, and $s$ is s-plane.

Using Equation (1), the DC motor transfer function can be expressed as

$\frac{\theta(s)}{\mathrm{U}_{a}(\mathrm{~s})}=\frac{\mathrm{k}_{m}}{\left(\mathrm{r}_{a}+\mathrm{L} s\right)\left(J_{m} s+B_{m} s\right)+\mathrm{k}_{m} \mathrm{k}_{b}}$

TABLE 1: DC MOTOR PARAMETERS

\begin{tabular}{|c|c|}
\hline Motor parameters & Value \\
\hline $\boldsymbol{r}_{\boldsymbol{a}}$ & $2.0 \mathrm{ohms}$ \\
\hline $\mathbf{L}$ & $0.5 \mathrm{Henry}$ \\
\hline $\mathbf{k}_{\boldsymbol{m}}$ & $0.1 \mathrm{~N} \cdot \mathrm{m} / \mathrm{A}$ \\
\hline $\mathbf{k}_{\boldsymbol{b}}$ & $0.1 \mathrm{~N} \cdot \mathrm{m} / \mathrm{A}$ \\
\hline $\boldsymbol{I}_{\boldsymbol{m}}$ & $0.02 \mathrm{Kg} \cdot \mathrm{m}^{2} / \mathrm{rad}$ \\
\hline $\boldsymbol{B}_{\boldsymbol{m}}$ & $0.2 \mathrm{~N} \cdot \mathrm{m}$ \\
\hline
\end{tabular}

\section{IMPLEMENTATION}

Fitness Function: for optimal control of dc motor using PID controller we used two fitness functions. Fitness function for first case is Integral of absolute error and is given as:

$I A E=\int_{0}^{t}|e(t)| d t$

Fitness function for second case is Integral of absolute time error and is given as:

$$
I A T E=\int_{0}^{t} t *|e(t)| d t
$$

\section{EQUILIBRIUM OPTIMIZATION ALGORITHM (EOA)}

This is novel population based metaheuristic optimization algorithm proposed by Faramarzi et.al [19].

Motivation: The algorithm is motivated from a simple wellmixed dynamic mass balance on a control volume, in which a mass balance equation is used to describe the concentration of a nonreactive constituent in a control volume as a function of its various source and sink mechanisms [19].

A first-order ordinary differential equation showing the generic mass-balance equation, wherein the change in mass in time is equivalent to the amount of mass which enters the system and adding the amount being produced in the system subtracting the amount that leaves the system, is described as: $V \frac{d C}{d t}=Q C_{e q}-Q C+G$

$C$ is the concentration which lies inside the control volume $\mathrm{V}$, $(\mathrm{dC} / \mathrm{dt})$ is the rate of change of mass in that control volume, $\mathrm{Q}$ is the volumetric flow rate into and out of the control volume, Ceq signifies the concentration at a balance state in which there is no consideration of generation inside the control volume, and $\mathrm{G}$ is the mass generation rate inside the control volume.

Solving eq (5)

$$
C=C_{e q}+\left(C_{0}-C_{e q}\right) F+\frac{G}{\lambda V}(1-F)
$$

F is calculated as: $F=\exp \left[-\lambda\left(t-t_{0}\right)\right] \quad \ldots(7)$

Where $t_{0}$ and $C_{0}$ are the initial values of start time and concentration, which depend on the integration interval. Equation (7) is used to evaluate the approximate value of concentrates present in the control volume with a specified turnover speed or it can also be used to compute the average turnover rate using a simple linear regression with a known generation rate and other conditions.

As Equation (6) depicts that there are three terms which present the updating instructions for a particle, and each particle updates its concentration via three separate terms. The first term is the equilibrium concentration, defined as one of the best-so-far explanations arbitrarily selected from a pool, called the equilibrium pool. The second term is related to concentration difference among a particle and the equilibrium state, which behaves as a straight search mechanism. This term inspires particles to globally explore the domain, acting as explorers. The last and final term is associated with the generation rate, which acts as an exploiter, or solution refiner, predominantly with small steps.

\subsection{Initialization and function evaluation}

The initial concentrations are built which are based on the quantity of particles and dimensions with constant random initialization in the search space as follows:

$$
C_{i}^{\text {initial }}=C_{i}^{\min }+\operatorname{rand}\left(C_{i}^{\max }-C_{i}^{\min }\right) \quad \mathrm{i}=1,2, \ldots \mathrm{n}
$$

$C_{i}^{i n i t i a l}$ is the initial concentration vector of the $i$-th particle, $C_{i}^{\min } \& C_{i}^{\max }$ are minimum and maximum values for the dimensions, Rand is a random vector in the interval of $[0,1]$, and $n$ is the number of particles as the population. Particles are evaluated for their fitness function and then are sorted to determine the equilibrium candidates.

\subsection{Equilibrium pool and candidates (Ceq)}

The equilibrium state is the concluding convergence state of the entire algorithm, which is preferred to be the global optimum. The five particles are nominated as equilibrium contenders which are used for creating a vector called the equilibrium pool:

$$
C_{\text {eq, pool }}=\left\{C_{\theta q(1)}, C_{\theta q(2)}, C_{\theta q(3)}, C_{\theta q(4)}, C_{\text {eq(avg) }}\right\}
$$

... (9)

These candidates prove to the best particles in the global space that are identified during the complete optimization procedure including an additional particle having a concentration which is the arithmetic mean of the stated four particles. These four candidates aid EOA to have an improved exploration capability, while the average candidate provided assistance in exploitation. Each particle present in each respective iteration updates its concentration with the random selection among candidates which are chosen with the identical probability.

\subsection{Exponential term $(F)$}

A precise definition of this term will support EO in having a rational balance among exploration and exploitation. Meanwhile the turnover rate is a varying parameter with time 
in an actual control volume, $\lambda$ is supposed to be a random vector in the interval of $[0,1]$.

$F=\exp \left[-\lambda\left(t-t_{0}\right)\right]$

Where time, $\mathrm{t}$, can be defined as a function of iteration (Iter) and thus declines with the number of iterations:

$t=\left(1-\frac{\text { Iter }}{M a x_{\text {iter }}}\right)^{\left(a_{2} \frac{\text { Iter }}{M a x_{i t e r}}\right)}$

Where Iter and $M a x_{\text {iter }}$ represent the current and the maximum number of iterations, respectively, and $a_{2}$ is a constant value that is used to accomplish exploitation ability.

\section{RESULTS \& DISCUSSIONS}

EOA is used to find $\mathrm{Kp}, \mathrm{Ki}, \mathrm{Kd}$ gains for PID control of dc motor. The number of population used for EOA was 20 and maximum number of iterations performed were 40 .

\section{Test case I: Neglecting Disturbance Torque.}

For this case dc motor parameters used are given in table 1. Unit step signal was given as input to simulation model given in fig.2. First the simulation was run with IAE as fitness function and then with IATE as fitness function.

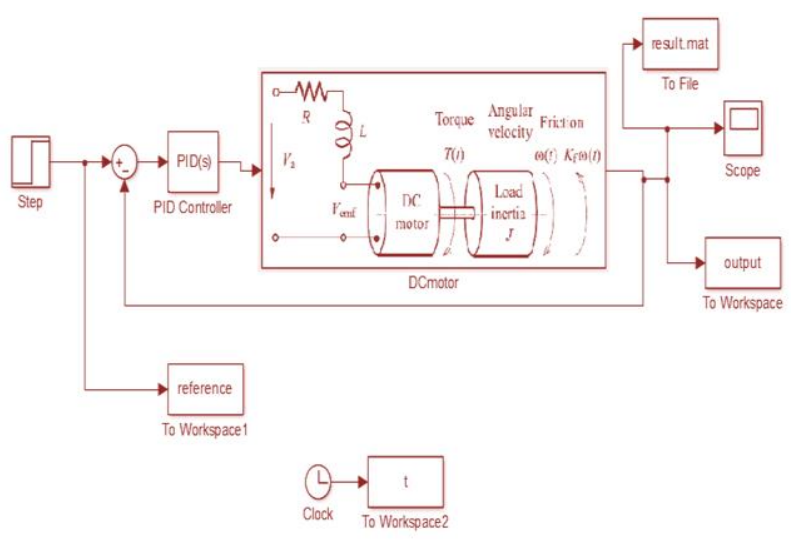

Fig.2. Simulation model of DC motor PID control

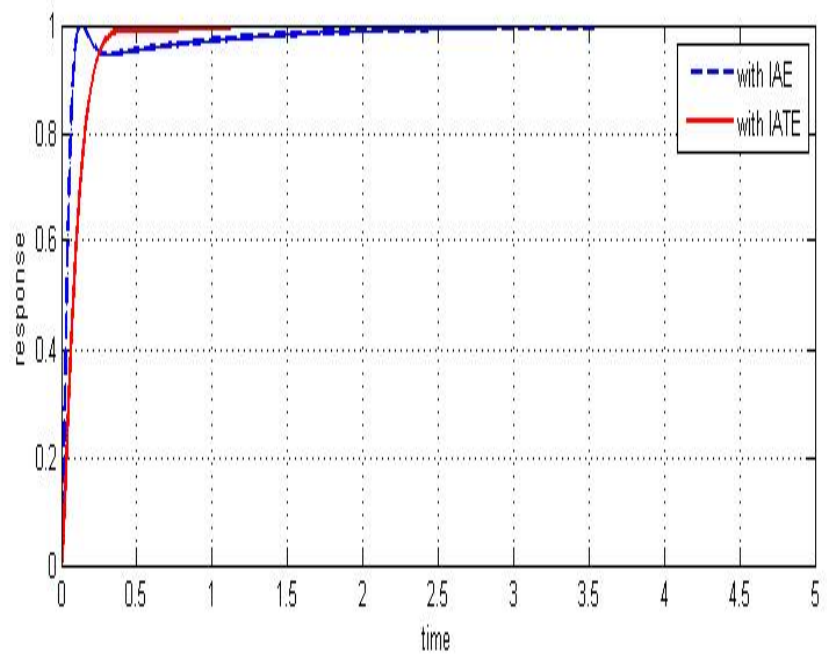

Fig.3. Simulation Results of DC motor PID control

\begin{tabular}{|c|c|c|c|c|c|c|}
\hline & & & & Parameter & $\mathrm{IAE}$ & IATE \\
\hline \multirow{2}{*}{ Parrmeter } & \multirow{2}{*}{ I } & & \multirow{2}{*}{ D } & Rise Time & 0.0660 & 0.1865 \\
\hline & & 1 & & Settling Time & 1.3423 & 0.31 \\
\hline \multirow{3}{*}{$\begin{array}{l}\text { Fitness function } \\
\text { (IAE) }\end{array}$} & \multirow{3}{*}{40} & \multirow{3}{*}{40} & \multirow{3}{*}{1.8221} & Settling VIin & 0.9019 & 0.9 \\
\hline & & & & Settling Nax & 0.9997 & 1.00 \\
\hline & & & & ersh & 0.0259 & 0 \\
\hline \multirow{2}{*}{$\begin{array}{l}\text { Fitness finction } \\
\text { (IATE) }\end{array}$} & \multirow{2}{*}{12.29234} & 40 & \multirow[t]{2}{*}{0734391} & Undershoot & 0 & 0 \\
\hline & & & & Peak & 0.9997 & 1.00 \\
\hline
\end{tabular}

Fig.4. Results for Test Case-I

Simulation results clearly reveal that EOA is performing good on tuning of PID parameters for DC motor control. Output results with IAE and IATE as fitness function were compared and clearly IATE is better choice for fitness function.

Test case II: Considering Disturbance Torque.

For this case dc motor parameters used are given in table 1. Unit step signal was given as input to simulation model given in fig.2. The simulation was run with IATE as fitness function.

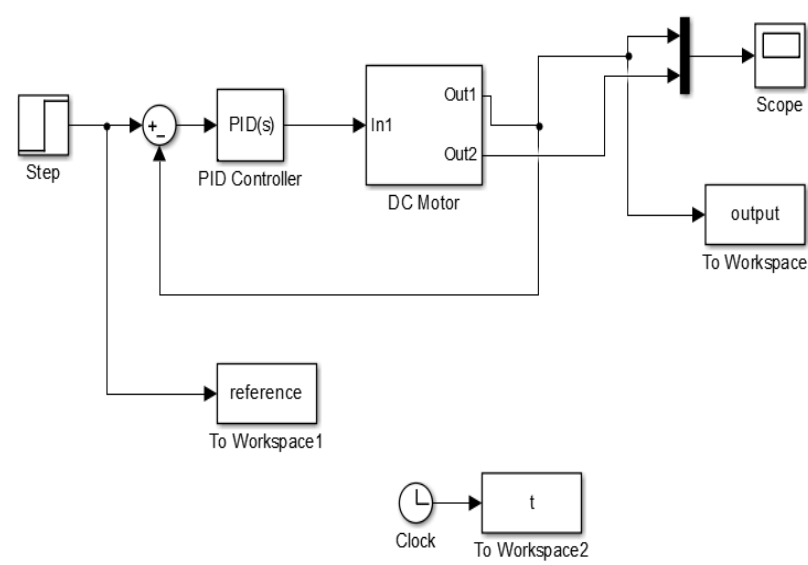

Fig.5. a) Simulation model of DC motor PID control

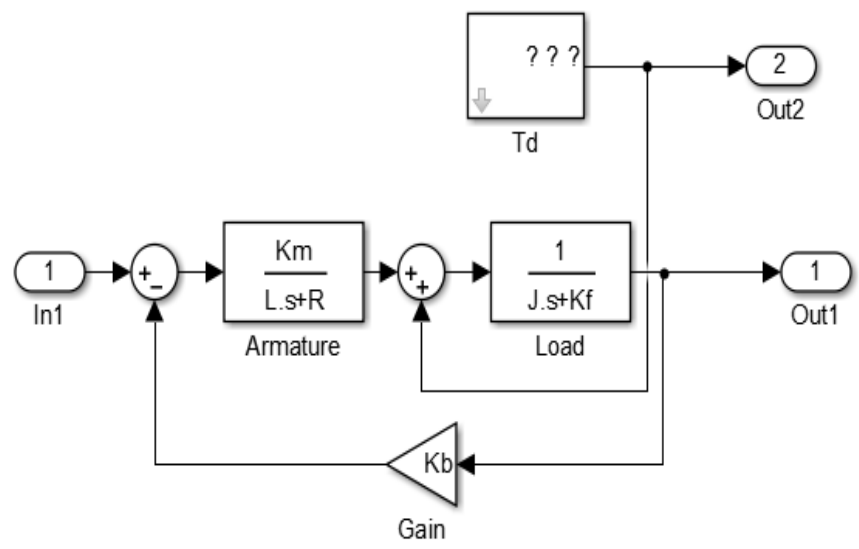

Fig.5. b) Sub model of dc motor with torque disturbance 


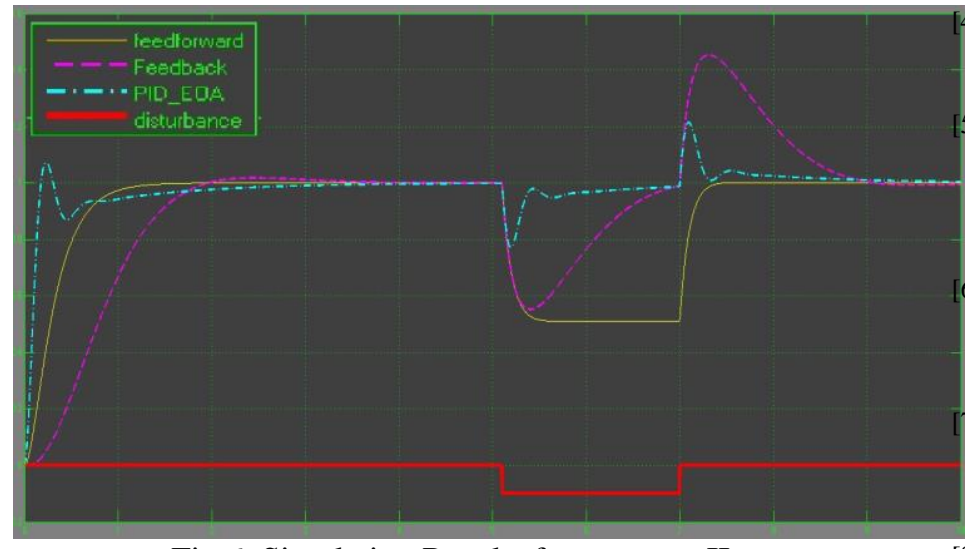

Fig.6. Simulation Results for test case II

Simulation was carried out with feedforward control method, feedback control, PID (tuned with EOA) control. Output results show that PID(EOA) is performing better in rejecting disturbances in torque.

\section{CONCLUSION}

It can be concluded form the literature that PID controllers are a prevalent solution for control because of their modest construction, usually satisfactory control performance and comfort of usage. In this presented work, PID controller has been tuned by means of Equilibrium Optimization Algorithm (EOA) over simulation of the speed control system of a DC motor. The implementation of the EOA algorithm method used for tuning a PID controller has been demonstrated and proved to be effective in rejecting load torque disturbance and in terms of parameters like system overshoot, settling time and rise time.

\section{ACKNOWLEDGMENT}

The research work presented here in this paper has been supported by our organization, DAV Institute of Engineering \& Technology, Jalandhar, Punjab, India. We thank the authorities and department of Electrical Engineering for all the support and guidance which assisted the research to go smoothly.

\section{REFERENCES}

[1] W. Cui, Y. Gong, and M. H. Xu, "A permanent magnet brushless DC motor with bifilar winding for automotive engine cooling application," IEEE Transactions on Magnetics, vol. 48, no. 11, pp. 3348-3351, 2012.

[2] A. Sathyan, M. Krishnamurthy, N. Milivojevic, and A. Emadi, "A lowcost digital control scheme for brushless DC motor drives in domestic applications," in Proceedings of the 2009 IEEE International Electric Machines and Drives Conference, pp. 76- 82, May 2009.

[3] P. C. Krause, O. Wasynczuk, and S. D. Sudhoff, Analysis of Electric Machinery and Drives, John Wiley \& Sons, 2013.
A. Andrzejewski, "The time-minimal and without overshoot speed control of DC motor," in Proceedings of the International Conference on Computer as a Tool (EUROCON '07), pp. 1792-1799, September 2007.

S. Galijasevi'c, `S. Ma`si'c, S. Smaka, A. Ak`samovi'c, and D. Bali'c, "Parameter identification and digital control of speed of a permanent magnet DC motors," in Proceedings of the 23rd International Symposium on Information, Communication and Automation Technologies, October 2011.

F. E. Hoyos, A. Rinc'on, J. A. Taborda, N. Toro, and F. Angulo, "Adaptive quasi-sliding mode control for permanent magnet DC motor," Mathematical Problems in Engineering, vol. 2013, Article ID 693685, 12 pages, 2013

7] H. Zhang, L. Ge, M. Shi, and Q. Yang, "Research of compound control for DC motor system based on global sliding mode disturbance observer," Mathematical Problems in Engineering, vol. 2014, Article ID 759147, 7 pages, 2014.

[8] J. Yao, G. Yang, Z. Jiao, and D. Ma, “Adaptive robust motion control of direct-drive DC motors with continuous friction compensation," Abstract and Applied Analysis, vol. 2013,Article ID837548, 14 pages, 2013.

[9] R. Namba, T. Yamamoto, and M. Kaneda, "Robust PID controller and its application," in Proceedings of the 1997 IEEE International Conference on Systems, Man, and Cybernetics, pp. 3636-3641, October 1997.

[10] Y. Harrath, B. Chebel-Morello, and N. Zerhouni, "A genetic algorithm and data mining based meta-heuristic for job shop scheduling problem," in Proceedings of the 2002 IEEE International Conference on Systems, Man and Cybernetics, pp.280-285, October 2002.

[11] X. Li and M. Yin, "Self-adaptive constrained artificial bee colony for constrained numerical optimization," Neural Computing and Applications, vol. 24, no. 3-4, pp. 723-734, 2014.

[12] Z. Cui and X. Gao, "Theory and applications of swarm intelligence," Neural Computing and Applications, vol. 21, no. 2, pp. 205-206, 2012.

[13] R. G. Kanojiya and P. M. Meshram, "Optimal tuning of PI controller for speed control of DC motor drive using particle swarm optimization," in Proceedings of the International Conference on Advances in Power Conversion and Energy Technologies (APCET '12), August 2012.

[14] Y. Wang, C. Xia, M. Zhang, and D. Liu, "Adaptive speed control for brushless DC motors based on genetic algorithm and RBF neural network," in Proceedings of the IEEE International Conference on Control and Automation (ICCA '07), pp. 1219-1222, June 2007.

[15] H. M. Asifa and S. R. Vaishnav, "Particle swarm optimization algorithm based PID controller," in Proceedings of the 3rd International Conference on Emerging Trends in Engineering and Technology (ICETET '10), pp. 628-631, November 2010.

[16] C. Cao, X. Guo, and Y. Liu, "Research on ant colony neural network PID controller and application," in Proceedings of the 8th ACIS International Conference on Software Engineering, Artificial Intelligence, Networking, and Parallel/Distributed Computing, pp. 253-258, August 2007.

[17] M. A. Sahib, B. S. Ahmed, and M. Y. Potrus, "Application of combinatorial interaction design for dc servomotor pid controller tuning," Journal of Control Science and Engineering, vol. 2014, Article ID 576868, 7 pages, 2014.

[18] Y.-C. Luo, Z.-S. Ke, and Y.-P. Kuo, "Sensorless rotor-field oriented controlled induction motor drive with particle swarm optimization algorithm speed controller design strategy ," Controller Design Strategy, vol. 2014,Article ID861462, 13pages, 2014

[19] [A. Faramarzi, M. Heidarinejad, B. Stephens et al., Equilibrium optimizer: A novel optimization algorithm, Knowledge-Based Systems (2019), doi: $\quad$ https://doi.org/10.1016/j.knosys.2019.105190. 